\title{
A comparison of methods for estimating soil characteristics in regional acidification models; an application of the MAGIC model to Scotland
}

\author{
Rachel C. Helliwell, ${ }^{1}$ Robert C. Ferrier, ${ }^{1}$ Christopher D. Evans ${ }^{2}$ and Alan Jenkins ${ }^{2}$ \\ 'Macaulay Land Use Research Institute, Craigiebuckler, Aberdeen, AB15 8QH, UK. \\ 2 Institute of Hydrology, Wallingford, Oxfordshire, OX10 8BB, UK.
}

\begin{abstract}
The results from an application of MAGIC (Model of Acidification of Groundwater In Catchments) to 733 Scottish catchments are presented. The availability of representative, good quality soil data is frequently a limiting factor for biogeochemical modelling, particularly those involving modelling at various spatial scales. This study tests the sensitivity of MAGIC to soil input data derived from two different methodologies; the 'nearest neighbour method' considers the closest representative soil profile to a catchment, and the 'spatial weighting method' of all soil types identified in a catchment, based on a soil physico-chemical classification of Scotland. Soil data (soil depth, density, cation exchange capacity and base saturation) calculated using the 'nearest neighbour method' and the 'spatial weighting method' were highly variable, although the range of upper and lower limits were greater for soil data produced using the nearest neighbour method. In contrast to the predominantly organic soil data calculated by the nearest neighbour method, the spatially weighted soil parameters included a greater proportion of mineral soils. With regard to simulated surface water Acid Neutralising Capacity (ANC) for 1851, 1997 and 2050, MAGIC predictions were similar irrespective of the methodology used to determine soil input parameters. However, soil input data derived from both methods resulted in variable base saturation predictions. It is concluded that the 'nearest neighbour' methodology is most appropriate if the objective is to determine the predicted response of the most acid-sensitive sites within a region in line with the approach used in Critical Load mapping. On the other hand, 'spatial weighting' integrates catchment soils and represents a more robust methodology by which to determine changes in median soil and water response in a regional context. The anticipated reductions in $S$ emissions associated with the Second S Protocol are predicted to have a marginal beneficial effect on the recovery of soils and surface waters of Scotland.
\end{abstract}

\section{Introduction}

The acidification of soils and waters over many industrialised regions, including Europe and North America, has been accelerated by the deposition of strong acid anions in acid precipitation, a direct result of large scale burning of fossil fuel. The rate of soil and water acidification can be highly variable depending on the biogeochemical characteristics of individual catchments. On large regional and national scales, soil physico-chemical characteristics may be used to assess the sensitivity of soils and surface waters to acidification (Sverdrup et al., 1990). Catchment-based dynamic models such as MAGIC (Model of Acidification of Groundwaters in Catchments) offer a means of predicting the likely responses to reduced acid inputs (Jenkins $e t$ al., 1997; Evans et al., 1998) and hence evaluating the result of legislative controls on sulphur (S) emissions such as the UNECE Second S Protocol.
Soil input parameters to the model are obtained by interrogating data mapped at a catchment scale, to encompass the spatial distribution of different soil types, and so incorporate the influence this may have on the resultant surface water quality. The availability of representative, good quality soil data is frequently a principal limiting factor for modelling especially at regional or national scale. A robust soil classification suitable for modelling applications at different spatial scales, is, therefore, an important requirement to assess the efficacy of current and future legislation.

The mapping and monitoring of soils has been undertaken throughout the European Union to various extents, and such information is fundamental to, among others, the assessment of environmental risk, soil conservation policies and sustainable development (Le Bas and Jamagne, 1996). In a Scottish context, the first national survey of soils was 
initiated in 1948 and continued in a structured way until 1987. Subsequent surveys have been focused on strategic studies, in particular the potential role of soils in ameliorating the impact of enhanced anthropogenic deposition (Langan and Wilson, 1994, and Hornung et al., 1995a,b). To date, these regional and national assessments of soil acidification have been limited to ranking the parent material and soil types according to different estimates of buffering capacities (Kinniburgh and Edmunds, 1986 and Hornung et al., 1995a,b). The Skokloster classification scheme (Nilsson and Grennfelt, 1988) was based on the principle whereby soil minerals were divided into five classes on the basis of their resistance to chemical weathering, and this classification has been applied to the soils of Scotland (Langan et al., 1995). The major parent materials from which most Scottish soils have developed are ultimately derived from acid to basic igneous rocks and till, schist, and other metamorphic types, Lower Paleozoic greywhackes and shales, Old Red Sandstone, Carboniferous sediments and Permo-Triassic sediments. Large areas of Scotland have soils derived from base-poor parent material, such as granites, and are identified as being highly sensitive to anthropogenic deposition. The soils developed from these parent materials are also closely associated with landform, geomorphology and climate, which can vary regionally and at the catchment scale. It is this latter scale which represents the fundamental spatial unit linking soils and waters.

The objective of this study was to predict the recovery of acid sensitive soils and surface waters in Scotland to the UNECE Second S Protocol. In particular, the aim was to determine how best to integrate soil data from mapped and point source information contained in a national database, given an understanding of the inherent variability in soils at a catchment scale. Two different soil assessment methodologies were investigated comparing a catchment based approach ('spatial weighting') with that of a point based approach ('nearest neighbour').

\section{Methodology}

\section{SITE SELECTION}

A network of sites in Scotland was selected as part of the UK Critical Loads Research Programme in 1993 (Kreiser et al., 1993). The water chemistry data collected during this programme were used in the present study as the target variables in the MAGIC calibration procedure. A detailed account of the sample collation, preparation and analysis is described by Kreiser et al. (1993). The site selection strategy adopted by Kreiser et al. (1993) ensured uniformity in the sample collection and analysis which is important for standardisation of large scale modelling applications. A sampling resolution of $10 \mathrm{~km}^{2}$ was applied to areas of high and medium sensitivity to acidification. Areas considered at low risk to acidification were sampled on a $20 \mathrm{~km}^{2}$ grid. The most sensitive freshwater body in each grid was sampled so that if the critical load for the selected catchment was not exceeded, it could be assumed that the remaining surface waters in the grid were unlikely to be acidified. Where possible, loch sites were sampled in preference to streams because loch chemistry is inherently more stable than stream chemistry. The majority of freshwater systems sampled in Scotland were lochs $(\oplus 70 \%)$ situated in the Scottish Highlands and Islands, and in the Galloway region of south-west Scotland. The remaining sites were streams (which predominate in north east Scotland), and isolated reservoirs in the Southern Uplands. The catchments were generally small with $71 \%$ (545 catchments) being $<2 \mathrm{~km}^{2}$ (Fig. 1a). The loch areas were small relative to the size of the respective catchments, with a loch:catchment ratio $<0.1$ for $70 \%$ of the Scottish sites (Fig. 1b). Although $28 \%$ of the sites were above $600 \mathrm{~m}$, and so prone to enhanced deposition through seeder-feeder mechanisms (Fowler et al., 1995), the remaining catchments were predominantly at low altitude (Fig. 1c).

The criteria for selecting individual freshwater catchments for sampling in a grid square included catchment sensitivity, altitude and catchment size. A Geographic Information System (GIS) overlay procedure, which incorporated soils, geology and land use data sets was used to produce a map which identified the most sensitive areas in each grid (Kreiser et al., 1993). Map units from the original geological sensitivity map of the UK (Kinniburgh and Edmunds, 1986) were assigned to one of four buffering capacity classes based on the mineralogy and geochemistry of the dominant rock types in each map unit (Hornung et al., 1995a). Soil sensitivity classes developed by Hornung et al. (1995a) were based on one of three buffering capacities identified by the mean base saturation and $\mathrm{pH}$ of the dominant soil series in each $1 \mathrm{~km}$ square (1:250,000 soil map). Forestry was not considered in the catchment selection criteria. The waterbody at the highest altitude in each grid was sampled as this was considered to be the most susceptible to acidification through enhanced atmospheric deposition (Kreiser et al., 1993). In addition, soils at high altitude are generally thin, highly leached and prone to acidify as a consequence of their characteristic low buffering capacities (Langan et al., 1994). A minimum loch size of $0.005 \mathrm{~km}^{2}$ was specified and large waterbodies extending between grid squares were excluded. It is noteworthy, therefore, that these catchments were selected on the basis of their sensitivity to surface water acidification as opposed to soil acidification.

\section{MAGIC MODEL}

The MAGIC model (Cosby et al., 1985a,b) was applied to 733 sites in Scotland. Biogeochemical models such as MAGIC require simplification of complex physicochemical processes that determine ion concentrations 

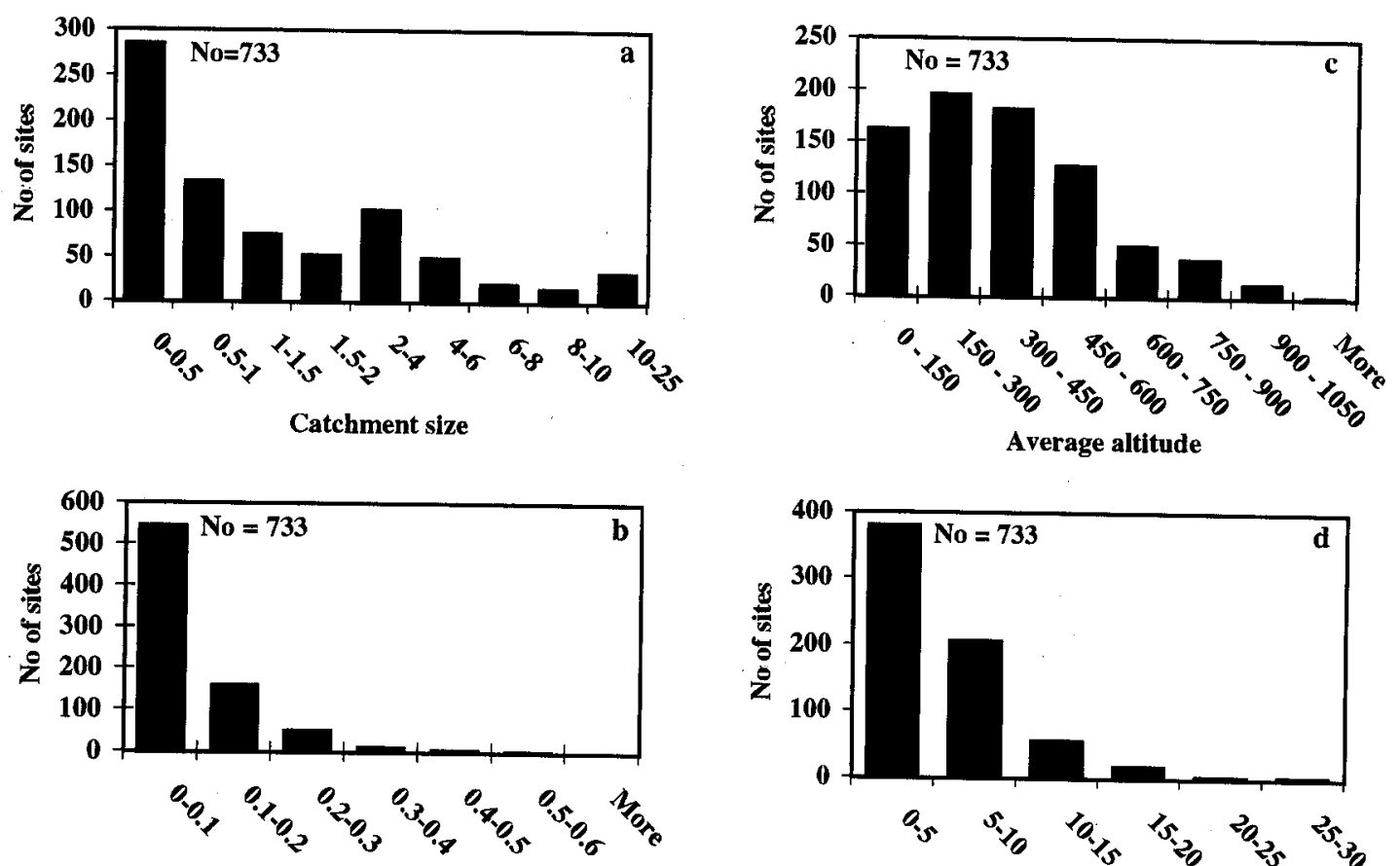

Loch: catchment ratio

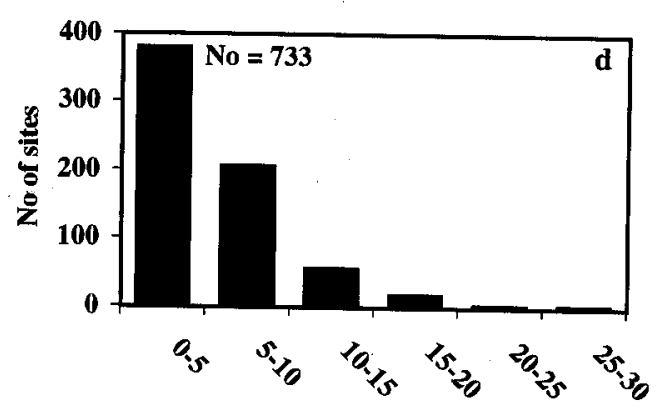

Distance of profile from catchment

Fig. 1. Frequency distribution of a) Catchment size $\left(\mathrm{km}^{2}\right)$, b) Loch:catchment ratio, c) Average altitude ( $m$ ), d) Distance of selected profiles from the catchments in the nearest neighbour method $(\mathrm{km})$.

throughout the soil column without affecting the model's ability to predict catchment scale responses (Jenkins et al., 1997). In assessing the adequacy of lumped models, such as MAGIC, for application to large scale heterogeneous catchments, two important issues must be considered. The first issue concerns 'process aggregation' and the degree to which numerous chemical processes can be represented by simple conceptualisations (Cosby et al., 1985a). The second issue concerns the scale of spatial heterogeneity where 'spatially aggregated' models such as MAGIC assume that the chemical and physical characteristics of the catchment are uniform. However, within this uniform system, MAGIC represents numerous very detailed chemical reactions. This study describes a multiple-site MAGIC application with two sets of soil input parameters derived from a nearest neighbour (point data) and spatial weighting (catchment based) method. These were developed to simplify soil physico-chemical parameters in the vertical and spatial dimension for modelling purposes. MAGIC was then calibrated with data from the surface water database collected as part of the UK Critical Loads Research Programme. The surface water chemistry and deposition parameters were applied to the nearest neighbour and spatially weighted calibrations. Full details of the input parameters used, and the procedure for calibration are described by Evans et al. (1998).

\section{SCOTTISH SOIL DATABASE}

The digitised Soil Map of Scotland $(1: 250,000)$ held at the Macaulay Land Use Research Institute (MLURI) provides information on parent material, soil associations, major soil sub-groups (MSSG), soil series, vegetation and landforms for all mapping units identified. The map units used on the Soil Maps of Scotland delineate soils with common physical attributes occurring within a defined geographical area, and often sub-divide soil associations. The soil associations comprise groupings of soil types developed on the same parent material. The National Soils Database (MLURI) contains detailed soil profile descriptions surveyed at the intersect of $5 \mathrm{~km}^{2}$ grids, and soil chemical and physical analysis from the intersect of $10 \mathrm{~km}^{2}$ grids (National Inventory Points), and soil data derived from other commissioned work.

\section{DEVELOPMENT OF THE POINT DATA BASED NEAREST NEIGHBOUR METHOD}

The nearest neighbour method relies on the availability of soil physico-chemical data within close proximity to 733 Scottish catchments. In the first instance, the dominant soil type in each catchment was identified by laying the digitised catchment boundaries over the digital Soil Map of Scotland. Following a search of all profiles in a 9 $\mathrm{km}^{2}$ grid surrounding each catchment, a profile with typical physical and chemical characteristics was taken to 
represent the dominant soil type (Fig. 2). To exclude soils with high concentrations of calcium $(\mathrm{Ca})$ and nitrogen $(\mathrm{N})$ from this study, natural soils were selected in preference to agricultural soils. For MAGIC calibrations the vertical heterogeneity of soil properties within a soil profile were lumped to provide one set of soil parameters. This vertical weighting procedure was adopted for cation exchange capacity (CEC), bulk density (BD) and exchangeable base cation fractions $\left(\mathrm{EX}_{x}\right)$.

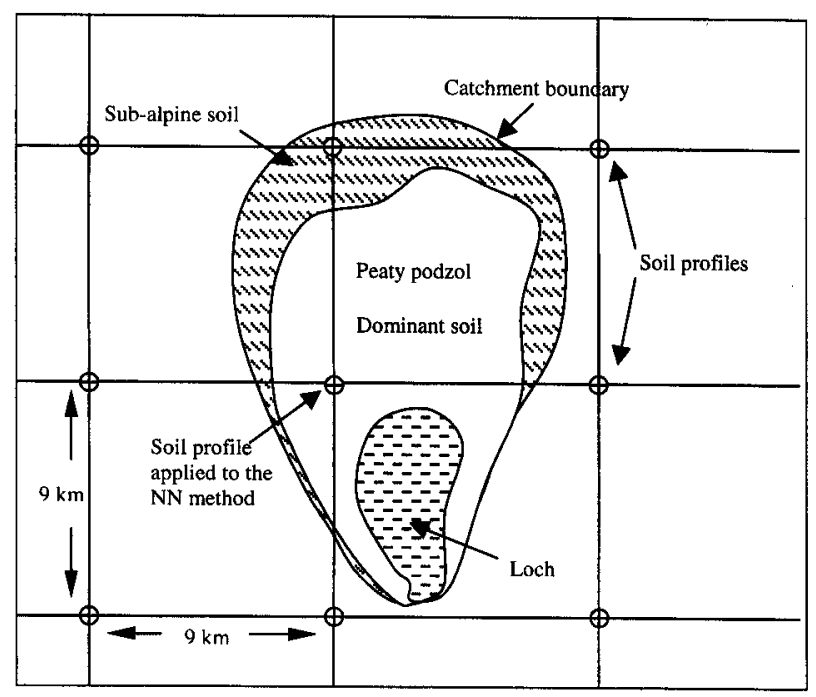

Fig. 2. Schematic of the nearest neighbour technique.

For bulk density the weighting procedure is given as:

$$
\mathrm{BD}_{\text {profile }}=\sum_{i=l, n} \mathrm{BD}_{i} \cdot \frac{d_{i}}{\sum_{i=l, n} d_{i}}
$$

Where $\mathrm{BD}_{\text {profile }}$ is the lumped profile bulk density, $\mathrm{BD}_{i}$ is the bulk density in horizon $i, d_{i}$ is the depth of horizon $i$ and $n$ is the number of soil horizons in the profile. Where no data exist for the bulk density of each horizon, estimates were based on the organic component of the soil. For $\mathrm{L}, \mathrm{H}$, and $\mathrm{O}$ horizons where loss on ignition (LOI) is between 70 and $100 \%, \mathrm{BD}$ was assumed to be $300 \mathrm{~kg} \mathrm{~m}^{-3}$; for A horizons with LOI between 60 and $69 \% \mathrm{BD}$ was assumed to be $1000 \mathrm{~kg} \mathrm{~m}^{-3}$; for $\mathrm{B}$ horizons with LOI between 30 and $59 \% \mathrm{BD}$ was assumed to be $1200 \mathrm{~kg} \mathrm{~m}^{-3}$; and, for C horizons with $\mathrm{LOI}<29 \%, \mathrm{BD}$ was assumed to be $1500 \mathrm{~kg} \mathrm{~m}^{-3}$ (Brady, 1984).

CEC is weighted by depth and BD for the soil profile, such that:

$$
\mathrm{CEC}_{\mathrm{profile}}=\frac{\sum_{i=1, n} \mathrm{CEC}_{i} \cdot \mathrm{BD}_{i} \cdot d_{i}}{\sum_{i=l, n}\left(\mathrm{BD}_{i} \cdot d_{i}\right)}
$$

and exchangeable base cation fractions $\left(\mathrm{EX}_{x}\right)$ are weighted by depth, BD and CEC, such that:

$$
\mathrm{EX}_{\text {profile }}=\frac{\sum_{i=l, n} \mathrm{EX}_{i} \cdot \mathrm{BS}_{i} \cdot d_{i}}{\sum_{i=l, n}\left(\mathrm{CEC}_{i} \cdot \mathrm{BD}_{i} \cdot d_{i}\right)}
$$

where $\mathbf{B S}=$ base saturation .

\section{DEVELOPMENT OF THE CATCHMENT BASED SPATIAL WEIGHTING METHOD}

A soil classification was developed from a databased search of profiles with complete soil descriptions and analytical data in $9 \mathrm{~km}^{2}$ areas surrounding each site. The total number of profiles selected represented a combination of associations and 'major soil sub-groups' (soil types). The classification of dominant soil types/associations was derived from a number of profiles representing each soil type/association that appeared in the search 50 times or more, combined with those soil types/associations with the greatest spatial cover in Scotland. A total of 35 soil types/associations classes was selected, which accounted for $60 \%$ of the total number of profiles identified in the search. Of the 580 map units identified in the $1: 250,000$ Soil Map of Scotland, 156 map units contributed to 35 soil classes used in this classification, which comprises $74 \%$ of the total area of Scotland.

Profiles extracted from the database were averaged by the $\mathrm{O}, \mathrm{A}, \mathrm{E}, \mathrm{B}$, and $\mathrm{C}$ horizons to generate one set of soil input parameters for each soil type in the classification (Soil Survey of Scotland, 1984). For each of the 35 dominant soil classes, mean soil physico-chemical parameters were calculated for each soil horizon for profiles selected in the $9 \mathrm{~km}^{2}$ search. Soil input parameters necessary for MAGIC calibrations include depth, bulk density, cation exchange capacity, exchangeable $\mathrm{Ca}, \mathrm{Mg}, \mathrm{Na}$ and $\mathrm{K}$, and base saturation which were vertically weighted by the procedure shown in Eqns. 1 to 3. This produces a set of vertically weighted soil data for 35 soil classes.

Two peat classes are distinguished from their physical and chemical properties and the hydrological status of the peat system (flushed or unflushed). In this classification, peat systems can be divided broadly into rain fed (ombrotrophic peat), which receive nutrients primarily from atmospheric deposition, and groundwater fed (minerotrophic/eutrophic peat). Following the segregation of the peat profiles into ombrotrophic and minerotrophic classes, the physical and chemical determinands were vertically weighted by the same procedure (as shown in Eqns. 1 to 3 ).

The vertically weighted soil parameters for each of the 35 classes are cross-referenced to the relevant map unit of the Soil Map of Scotland $(1: 250,000)$. The digitised catchment boundaries were overlaid onto the Soil Map of Scotland and the spatial extent of the map units were cal- 
culated using a GIS. For catchments with more than one map unit, the soil parameters from the 35 classes were weighted according to their spatial coverage in the catchment such that:

$$
\mathrm{V}_{\text {catch }}=\sum_{i=l, n} \mathrm{~V}_{\text {profile }} \cdot f_{i}
$$

Where $\mathrm{V}_{\text {catch }}$ is the aggregated soil characteristic for the catchment, $\mathrm{V}_{\text {profile }}$ is the profile lumped parameter, $f_{i}$ is the proportion of the catchment dominated by soil type $i$ and $n$ is the number of soil types present. This process generates a single value for each parameter which is both depth and spatially weighted across the catchment. Soil base saturation (BS) is calculated as the weighted sum of the individual base exchange fractions.

\section{Results and discussion}

The majority of profiles selected from the national soil database using the nearest neighbour method were within close proximity to the catchments. The distance of the selected profile from the catchment was less than $5 \mathrm{~km}$ for 379 catchments, with the majority of these profiles located within the catchment boundaries. A further 265 profiles were $<10 \mathrm{~km}$ from the catchments. All profiles used in this application were within $40 \mathrm{~km}$ of their respective catchments (Fig. 1d).

In contrast, the classification derived from the spatial weighting method represents the best estimate of soil parameters associated with natural soils in Scotland. The classification comprises 35 classes, which represent a combination of 15 soil associations and 11 soil types. A summary of this physico-chemical classification is presented in Table 1.

\section{DISTRIBUTION OF ACIDIFIED AND NON-ACIDIFIED SOILS IN SCOTLAND}

The areas in Scotland most at risk from soil acidification were identified from analyses of spatial and chemical soil data, in particular the soil base saturation. Estimates of soil CEC and base saturation derived from the nearest neighbour and spatial weighting methodologies were used to assess the spatial distribution of acid sensitive soils in Scotland. Non acidified soils were found to occupy large areas of the Midland Valley, south-east Scotland and a small area in the north-east. These soils are typically found in areas with gentle slopes, and are frequently associated with glacial till or easily weatherable parent material. Chemical analyses of soils in these regions indicate that soils derived from the Sourhope, Balrownie and Thurso associations (Fig. 3) are base rich (base saturation in the range $20-50 \%$ ).

Most of Scotland, however, is dominated by strongly acidified soils (base saturation $<10 \%$ ) particularly in large areas to the north of the Highland Boundary Fault and to the south of the Southern Upland Fault. The Galloway region of south-west Scotland, where the soils are basepoor, is particularly susceptible to acidification. Soil data indicate that acid sensitive soils in these regions are typical of the Dalbeattie, Ettrick and Arkaig associations (Fig. 3 ), developed on granite, schists, and greywackes. Peat is the most extensive soil type in Scotland $\left(7660 \mathrm{~km}^{2}\right)$ and as a result represents the largest number of profiles in the soil database (800 profiles). Minerotrophic and ombrotrophic peats are associated with the gently undulating topography of the Scottish foothills and upland plateaus. These peat soils occur in the same geographic areas as the other acid sensitive soil types. The distribution of acidified ombrotrophic peat has been shown to reflect spatial differences in acid deposition across Scotland (Skiba et al., 1989). In this study, base saturation derived from the spatially weighted method was $10 \%$ for ombrotrophic peat (Table 1). Minerotrophic peats were found to be slightly less susceptible to acidification as a result of their development on base rich geology or the influence of nutrient rich groundwater (Hornung et al., 1995a,b).

\section{COMPARISON OF THE - NEAREST NEIGHBOUR AND} SPATIAL WEIGHTING METHODOLOGIES

Soil parameters generated using the nearest neighbour method were compared with corresponding data derived from the spatially weighted method for all catchments. In contrast with the spatially weighted soils, data calculated using the nearest neighbour method were highly variable, representing a larger range of soil types and characteristics (Fig. 4). Soil depth varied from $0.1-2.0 \mathrm{~m}$ with the nearest neighbour method, and $0.5-1.2 \mathrm{~m}$ when using the spatial weighting approach. It is unlikely therefore, that shallow soils will feature using the latter approach unless the dominant soil in a catchment is thin, poorly developed skeletal soil (Fig. 4a). A large proportion of the nearest neighbour generated soils are organic, or are predominantly organic, and consequently have a higher cation exchange capacity than corresponding data derived from the spatially weighted method (Fig. 4b). In contrast to the nearest neighbour data, the high base saturation, typical of spatially weighted soils data reflected a greater contribution from mineral dominated horizons (Fig. 4c). The number of sites with acidified soils (BS $<10 \%$ ) was greater with soil data derived from the nearest neighbour method compared with those derived from the spatially weighted soil classification. However, the number of sites with non acidified soils (BS $>10 \%$ ) was largely independent of the methodology used to extract data from the soils database (Fig. 5).

From this analysis, it would appear that for acidification risk assessment methodologies such as Critical Loads, the nearest neighbour approach would represent the most highly sensitive soils associated with particular geographical locations. This would represent the best approach to 
Table 1. Soil classification derived from the spatial weighting method.

\begin{tabular}{|c|c|c|c|c|c|c|c|}
\hline Association & Soil type & $\begin{array}{c}\text { Total area of } \\
\text { soil association } \mathrm{km}^{2}\end{array}$ & $\begin{array}{l}\text { Number of } \\
\text { profiles }\end{array}$ & $\begin{array}{l}\text { Depth } \\
\text { m }\end{array}$ & $\begin{array}{c}\mathrm{BD} \\
\mathrm{kg} / \mathrm{m}^{3}\end{array}$ & $\begin{array}{c}\mathrm{CEC} \\
\mathrm{meq} / \mathrm{kg}\end{array}$ & $\begin{array}{l}\text { BS } \\
\%\end{array}$ \\
\hline Alluvial soil & Alluvial soil & 1260 & 59 & 0.77 & 1203 & 124 & 11 \\
\hline Arkaig & Peaty Podzol & & 265 & 1.04 & 1187 & 90 & 8 \\
\hline Arkaig & Peaty Gley & & 246 & 0.95 & 1135 & 90 & 9 \\
\hline Arkaig & Peaty Gleyed Podzol & & 166 & 1.08 & 1111 & 107 & 16 \\
\hline Arkaig & Humus Iron Podzol & & 123 & 0.88 & 1280 & 77 & 8 \\
\hline Arkaig & Alpine Podzol & 12502 & 83 & 0.74 & 1249 & 79 & 3 \\
\hline Balrownie & Humus Iron Podzol & 1412 & 50 & 0.8 & 1321 & 101 & 20 \\
\hline Corby & Humus Iron Podzol & & 121 & 0.96 & 1158 & 58 & 6 \\
\hline Corby & Peaty Podzol & 2377 & 104 & 1.32 & 1183 & 104 & 12 \\
\hline Countesswells & Humus Iron Podzol & & 243 & 0.88 & 1183 & 100 & 3 \\
\hline Countesswells & Peaty Podzol & & 236 & 0.93 & 1076 & 139 & 6 \\
\hline Countesswells & Alpine Podzol & & 170 & 0.72 & 1238 & 77 & 3 \\
\hline Countesswells & Peaty Gleyed Podzol & & 140 & 0.98 & 1122 . & 93 & 4 \\
\hline Countesswells & Peaty Gley & & 125 & 1.01 & 1102 & 102 & 14 \\
\hline Countesswells & Humus Podzol & 4435 & 60 & 0.75 & 1,300 & 253 & 1 \\
\hline Dalbeattie & Peaty Podzol & & 59 & 1 & 1145 & 117 & 6 \\
\hline Dalbeattie & Peaty Ranker & & 54 & 0.33 & 1076 & 164 & 2 \\
\hline Dalbeattie & Peaty Gley & 4435 & 51 & 1.05 & 1109 & 79 & 17 \\
\hline Darleith & Brown Earth & 2721 & 107 & 0.5 & 972 & 216 & 14 \\
\hline Dulsie & Peaty Podzol & 189 & 74 & 1.36 & 1231 & 64 & 11 \\
\hline Ettrick & Peaty Podzol & & 121 & 0.89 & 1125 & 162 & 4 \\
\hline Ettrick & Peaty Gley & & 118 & 0.92 & 1107 & 130 & 8 \\
\hline Ettrick & Brown Earth & & 86 & 0.69 & 1268 & 109 & 10 \\
\hline Ettrick & Peaty Gleyed Podzol & 7141 & 68 & 0.97 & 1145 & 127 & 5 \\
\hline Foudland & Peaty Gley & & 84 & 1.07 & 1252 & 77 & 14 \\
\hline Foudland & Humus Iron Podzol & 2508 & 66 & 0.97 & 1340 & 74 & 12 \\
\hline Organic & Ombrotrophic & & 525 & 0.79 & 448 & 567 & 10 \\
\hline Organic & Minerotrophic & 7660 & 275 & 1.02 & 384 & 764 & 12 \\
\hline Sourhope & Brown Earth & 1310 & 84 & 1 & 1246 & 132 & 46 \\
\hline Strichen & Humus Iron Podzol & & 295 & 0.81 & 1395 & 79 & 7 \\
\hline Strichen & Peaty Gley & & 117 & 1.01 & 1141 & 118 & 29 \\
\hline Strichen & Peaty Podzol & 6151 & 82 & 0.91 & 1175 & 166 & 5 \\
\hline Thurso & Peaty Gley & 1037 & 89 & 1.03 & 1114 & 107 & 28 \\
\hline Torridon & Peaty Gleyed Podzol & & 56 & 1.17 & 1160 & 51 & 15 \\
\hline Torridon & Peaty Gley & 1735 & 54 & 0.85 & 1100 & 84 & 7 \\
\hline
\end{tabular}

define limits for the protection of sensitive ecosystems, but is very much limited by the provision of point data in potentially remote locations. At a catchment scale, however, where potentially there are numerous different soil types, a spatial weighting procedure would result in a more quantitative description of lumped characteristics. This approach would be more suitable for regionalisation to larger scales and for extrapolation to areas of limited point data. However, it is noteworthy that this technique is dependent upon the availability of mapped data. The approach is more generic, and it is clear that the analysis results in the definition of median chemical characteristics for the catchment soils (Table 2). 


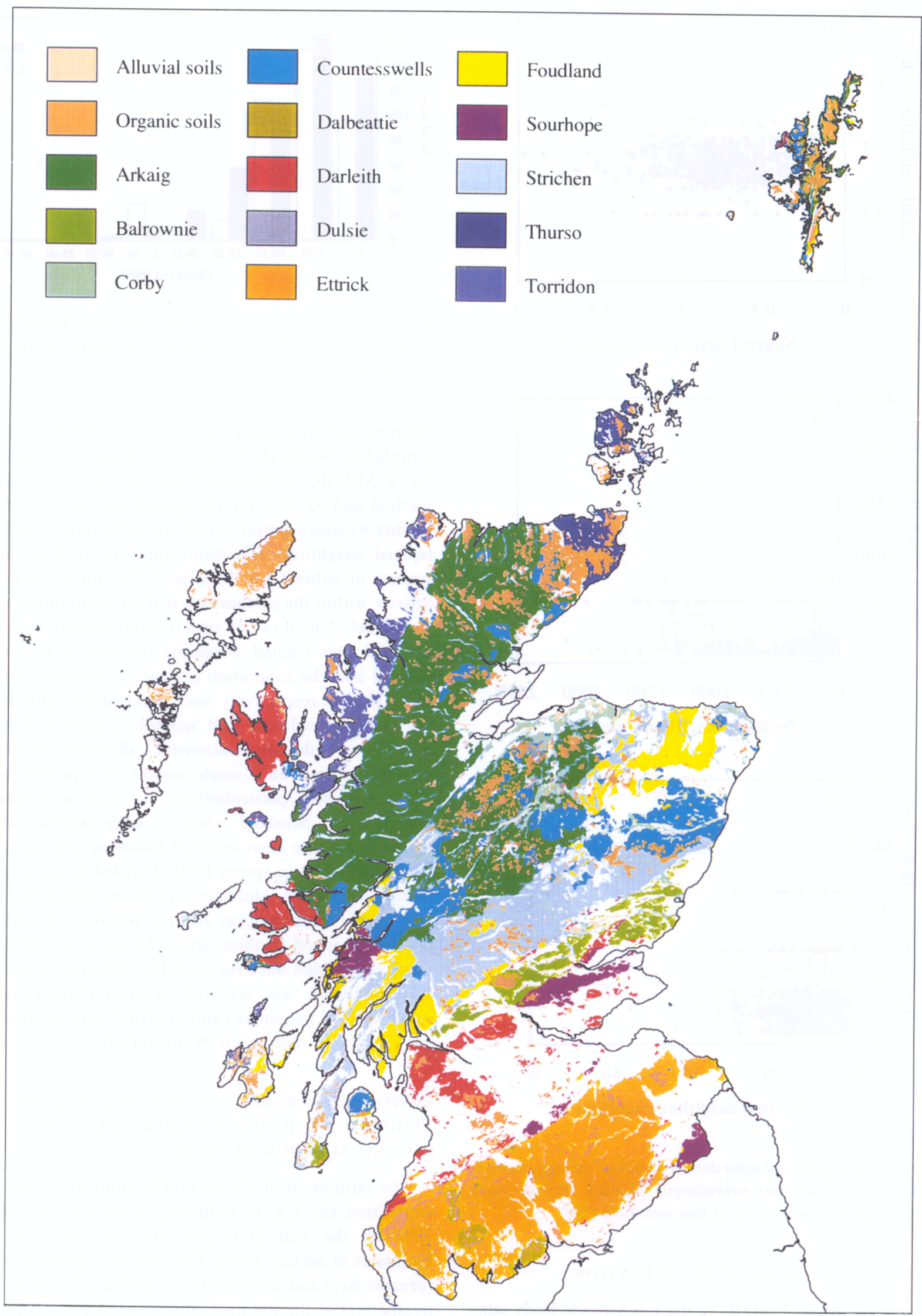

Fig. 3. Soil associations represented by the spatial meighting technique. 

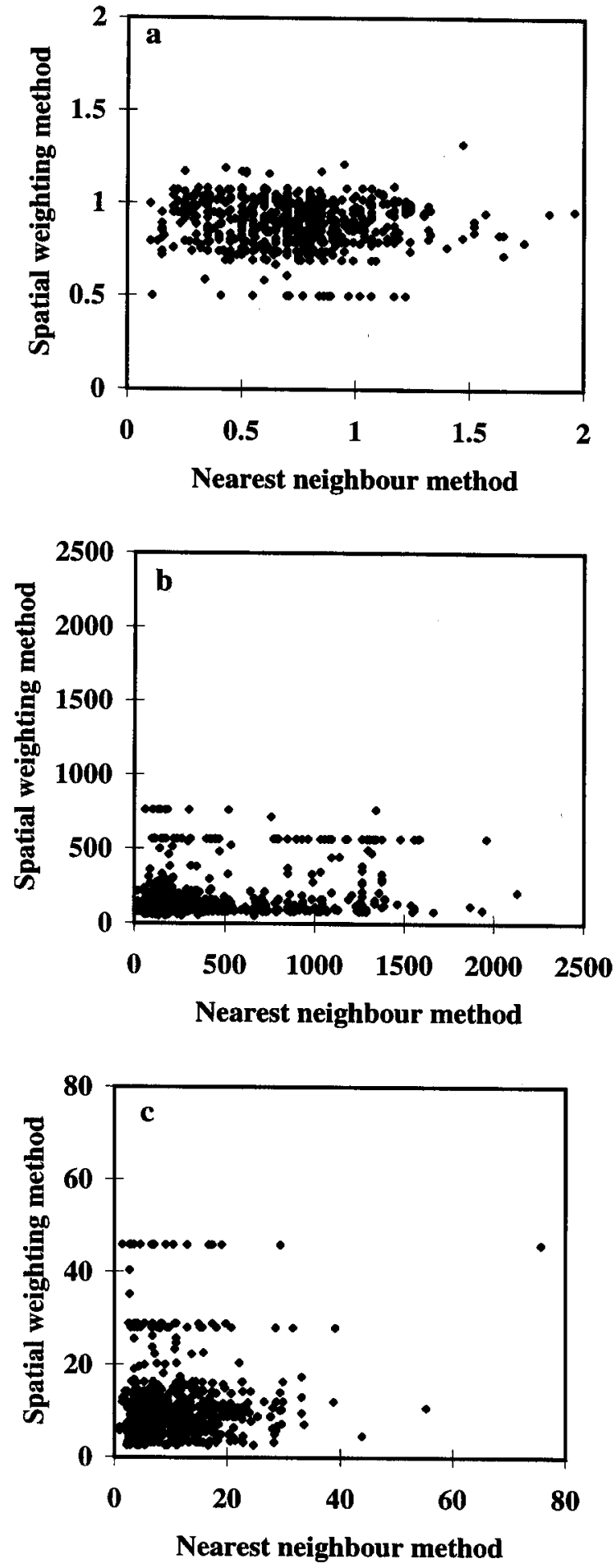

Fig. 4. Comparison of soil input data derived from the nearest neighbour and spatial meighting methodologies a) depth (m), b) cation exchange capacity (meq $\left.\mathrm{kg}^{-1}\right)$, c) base saturation (\%).

\section{MODEL CALIBRATION AND VALIDATION}

The application of MAGIC to the UK Critical loads sample sites is described by Evans et al. (1998), where full details of the input data used, and the procedures for cal-

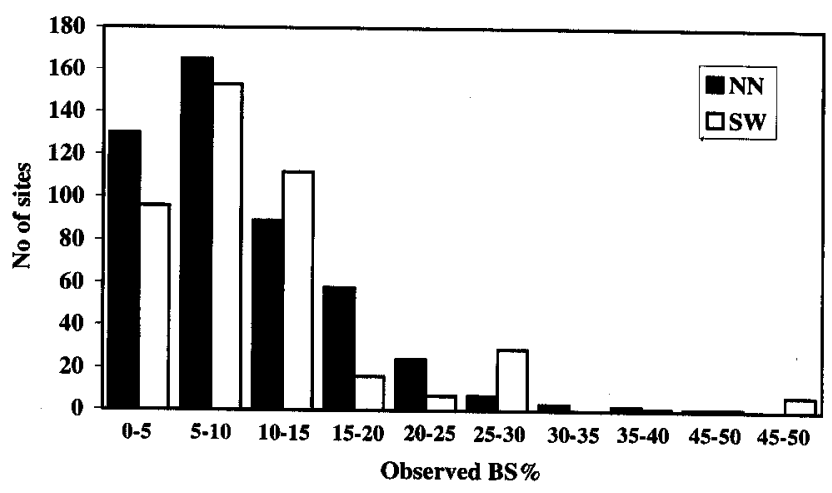

Fig. 5. Frequency distribution of base saturation derived from the nearest neighbour and spatial weighting methodologies for the Scottish catchments.

ibration and forecasting are described. Of the 733 sites sampled in Scotland, 13 sites lacked sufficient input data for a MAGIC calibration from the nearest neighbour method and 42 sites for the spatial weighting method. A further 85 sites (nearest neighbour calibration) and 82 sites (spatial weighting calibration) appeared to have internal sources of either $\mathrm{Cl}$ or $\mathrm{SO}_{4}$ (probably due to agricultural activity within the catchment), making them unsuitable for the model. A total of 635 sites (nearest neighbour method) and 609 sites (spatial weighting method) were therefore entered into the calibration procedure. Subsequently, 448 and 431 sites respectively were successfully calibrated for the nearest neighbour and spatially weighted data. The main factor inhibiting successful calibration of MAGIC was the reliance on a single sample to represent surface water chemistry, particularly in coastal areas of Northern and Western Scotland where a large number of sites appeared to have been sampled following a major sea salt deposition event in spring 1990. This led to unrepresentative surface water solute concentrations which the model was unable to reproduce, and the majority of calibration failures occurred in these areas (Evans et al., 1998). For those sites which were successfully calibrated, a successful correspondence was achieved between observed surface water and soil parameters and modelled present day chemistry $\left(\mathrm{r}^{2}=0.99\right.$ and $\mathrm{r}^{2}=0.99$ respectively).

\section{RESPONSE OF SOILS AND SURFACE WATERS TO REDUCED S EMISSIONS UNDER THE UNECE SECOND SULPHUR PROTOCOL}

The ratification of the Second S protocol in June 1994, committed the UK to reducing national $\mathrm{S}$ emissions by $70 \%$ by the year 2005 and $80 \%$ by the year 2010 . Estimates of surface water ANC for 1851 (hindcast), 1997 (present day) and 2050 (forecast) produced similar results irrespective of the soil methodology used to determine soil input paramieters for MAGIC applications. These are indicated by the strong positive correlations shown by linear 
Table 2, Advantages and disadvantages of the nearest neighbour and spatial weighting techniques.

\begin{tabular}{ll}
\hline & Advantages \\
\hline NEAREST NEIGHBOUR & $\begin{array}{l}\text { 1. Where local catchment variables } \\
\text { such as rainfall, deposition, parent } \\
\text { mETherial, drainage and vegetation are } \\
\text { spatially important }\end{array}$
\end{tabular}

2. Observed profile descriptions and measured chemical parameters

SPATIAL WEIGHTING METHOD
1. In large scale studies where observed soil data are limited, spatially weighted soils data may provide the best estimate of soil physico-chemical characteristic

2. Physico-chemical soil parameters are spatially and vertically aggregated, and therefore account for all soil types identified at a catchment scale

3. The spatial weighting classification is very versatile and may be applied to any number of natural systems in Scotland

4. In general physico-chemical parameters for soils of the same class (Table 1) were similar irrespective of geographical location

5. This method has been adopted in England and Wales

\section{Disadvantages}

1. No spatial representation of soil physico-chemical parameters at the catchment scale

\section{Dependant upon high resolution/} high quality data

3. The distance of a representative profile to catchments in remote, inaccessible mountain regions may be considerable

1. The averaging procedure used in this method resulted in a narrow range of soil parameters i.e. soil depth, base saturation, and cation exchange capacity (Fig. 4)

2. Spatially weighted data may not adequately represent catchments with highly sensitive soils as the range of soil parameters are narrow compared with data derived from the nearest neighbour method

3. Only the dominant soil types and associations are included in this classification regression of these relationships ( $r=0.99$ in both cases). Unmeasured parameters, such as the base cation weathering rates, were optimised during the multiple calibrations undertaken for each site. The weathering rate is adjusted during the optimisation procedure so that MAGIC is able to 'hit' the target variables (surface water concentrations of $\mathrm{Ca}, \mathrm{Mg}, \mathrm{Na}$ and $\mathrm{K}$, and soil exchangeable fractions of the same ions) irrespective of the soil input data used in the applications.

Figs. $6 a$ and $b$ show the water chemistry predicted by MAGIC for the acid sensitive sites (defined as having a present day $\mathrm{ANC}<50 \mu \mathrm{eq} \mathrm{l}^{-1}$ ), in response to historical changes in sulphur deposition and those associated with the Second S Protocol. This indicates that presently acidified surface waters will not recover to 1851 levels by 2050 , as it is doubtful that $\mathbf{S}$ deposition will decline to pre-industrial levels. The most intensely acidified sites in Scotland are those with present day surface water ANC $<0 \mu \mathrm{eq} \mathrm{I}^{-1}$. Such sites are located in areas of sensitive geology and moderate levels of anthropogenic deposition. For example, in Galloway (SW Scotland) the most acid sites are situated on a granitic pluton, with deep peat overlaying parent material developed on the Dalbeattie association. These results indicate that further reductions in $\mathrm{S}$ emissions beyond those stipulated by the Second S Protocol are necessary in regions with highly sensitive soils and geology, if surface water ANC and soil base saturation is to recover (ANC $>0 \mu \mathrm{eq} \mathrm{I}^{-1}$ and BS $>10 \%$ respectively).

For a limited number of sites which exhibit an inherent natural acidity, however, reducing anthropogenic $S$ beyond the requirements of the Second S Protocol is likely to be of limited net environmental benefit. For example, Loch Grannoch in Galloway is one of the most acidified catchments in Scotland, and even if all non-marine $S$ 

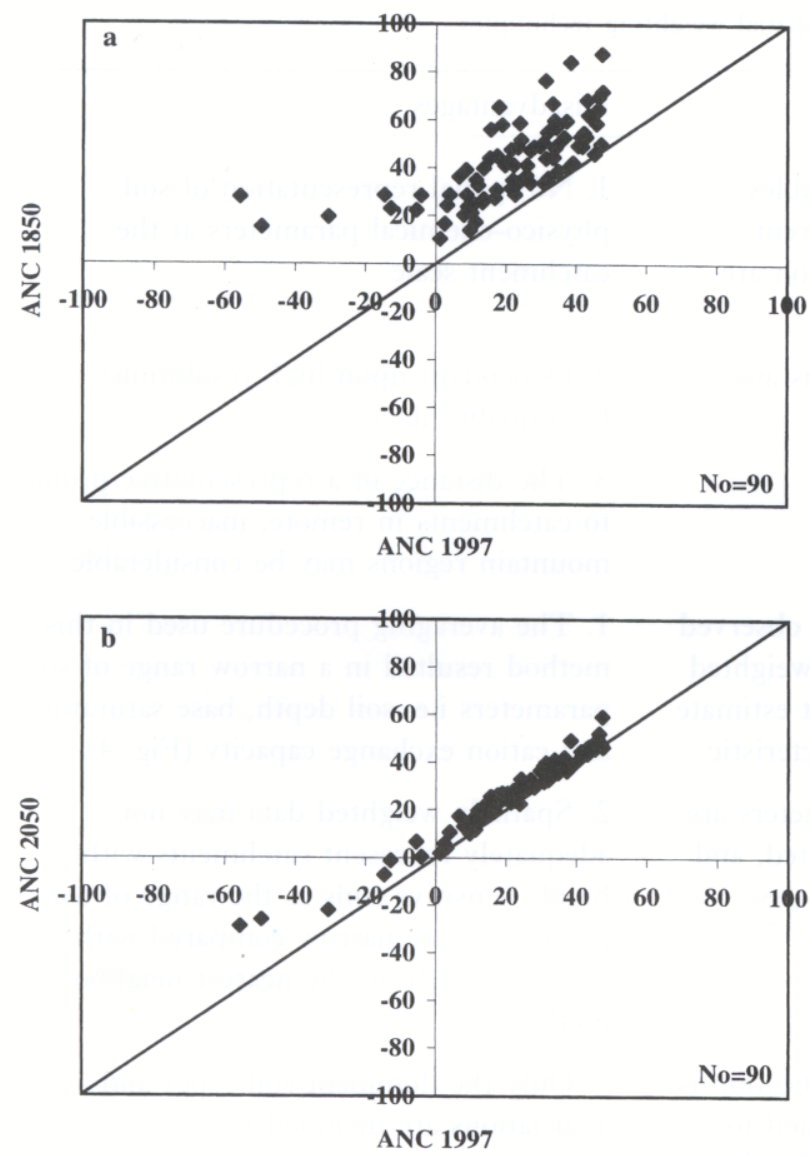

Fig. 6. Comparison of MAGIC simulated ANC ( $\mu$ eq $\left.t^{-1}\right)$ (a) 1851 and 1997, (b) 2050 and 1997. deposition were to be removed immediately, surface water ANC would not recover to $0 \mu \mathrm{eq} 1^{-1}$ within 50 years (Jenkins et al., 1997).

The agreed reductions in $\mathrm{S}$ emissions are also not adequate to induce a significant base saturation increase for sensitive soils in Scotland (as predicted for 2050), irrespective of the soil classification scheme used for the analysis (Fig. 7). The point-data based nearest neighbour approach identifies a greater spatial extent of continued depletion in base cation pools in these sensitive soils. In addition, these results indicate that the deposition of $S$ in 2050 remains significant compared to the supply of base cations derived from weathering. The deterioration in soil base saturation between 1997 and 2050 was predicted for 162 sites (nearest neighbour soil data) and 131 sites (spatially weighted soil data) respectively. This result is important as a small change in base saturation in acidified soils will result in higher levels of aluminium $(\mathrm{Al})$ in soil solution which can have serious implications on soil and water biology (Reuss and Johnson, 1985). The percentage change in soil base saturation reveals that more sites in the upland areas of Scotland will acidify from 1997 to 2050 with the nearest neighbour data than with data derived from spatially weighted method (Fig. 7). A clear spatial gradient of soil acidity is shown in Fig. 7, with the lowest soil base saturation in the high rainfall, upland regions of Scotland (N.W Highlands, Grampian Mountains, Southern Uplands and Galloway). Forecasts with both sets of soil data indicate a continued decline in base saturation from 1997 to 2050 for catchments with acid sensitive geology in

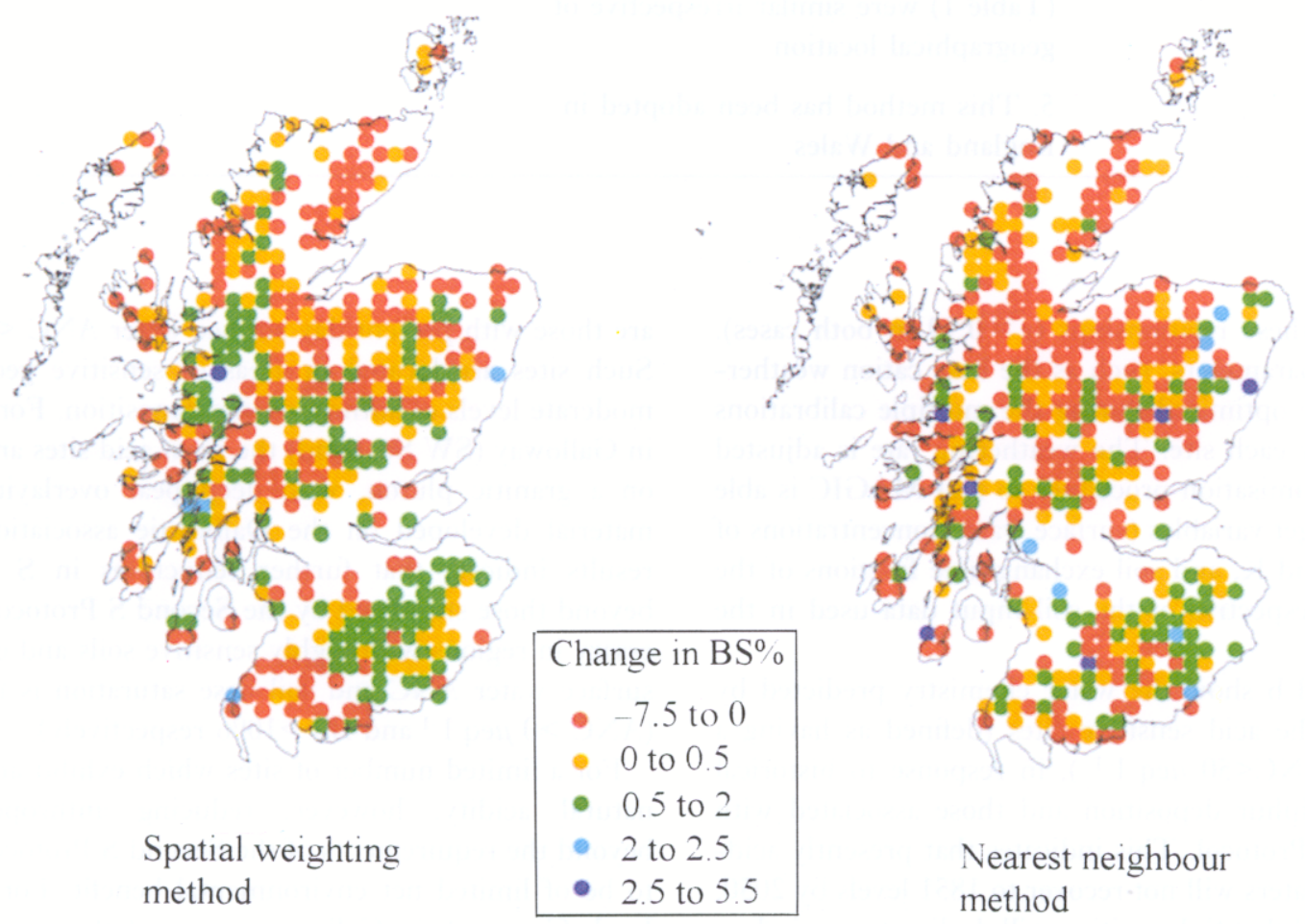

Fig. 7. Predicted percentage change in soil base saturation from 1997 to 2050: in response to the UNECE Second S Protocol. 
the Galloway region and Aberdeenshire. The spatial distribution of acid soils in this study corresponds to the soil Critical Load classes $0.2-0.5 \mathrm{keq} \mathrm{H}^{+} \mathrm{ha}^{-1}$ year $^{-1}$ (Hornung et al., 1995c). These classes are also indicative of the most sensitive soils in Scotland. Areas where the critical loads for acidity of soils are exceeded are also prone to soil acidification as indicated in this study. Soils in the north east of Scotland and the Midland Valley are non-acidified with present day (1997) and predicted (2050) base saturation ranging from $20-30 \%$. These regions are associated with basic igneous geology. In circumstances where no recovery is predicted from 1997-2050, it can be assumed that soils are naturally acidified and occur in areas with low acid deposition (Fowler et al., 1995; DOE, 1994). In this instance, the $S$ Protocol will have a negligible impact on regions such as the North West of Scotland where naturally acidified soils are common.

\section{Conclusions}

Dynamic models can provide an important role in making strategic decisions relating to the impact of acid emissions on soil and water chemistry. MAGIC, like other processbased models, is a simplified representation of complex catchment processes. As a result, the model includes spatial aggregation, and some fundamental simplifying assumptions have been made (e.g. soils and their associated waters are assumed homogeneous).

This study provides the first opportunity to test the sensitivity of MAGIC to soil input data derived from two very different methods; the point-data based nearest neighbour and catchment based spatially weighted methodologies. The soil input data derived from both methods identified the inherent variability typical of natural soil conditions. It was not the intention of this study to select one soil methodology in preference to the other, but to highlight the possibilities and constraints of determining soil characteristics from both mapped and point source data. To determine the efficacy of European Environment Policy there is a requirement to extrapolate systems understanding through modelling from the individual site to region, using mapped information. This study has highlighted that the use of such mapped data underestimates potentially the most extreme behaviour of catchment soils in response to such policy initiatives.

\section{Acknowledgements}

We would particularly like to thank M. Kernan and C. Curtis of the Environmental Change Centre, University College London for providing digital catchment boundaries necessary for the development of soil methodologies described in this paper. The authors are particularly grateful to S. Moir (MLURI) for his assistance with this project. This work was supported in part by the UK Department of the Environment (under contract Nos: EPG 1/3/65; EPG 1/3/73; EPG 1/3/51), the Department of the Environment Northern Ireland, the Commission of European
Communities (DYNAMO project ENV4-CT95-0030) and the Scottish Office Agricultural, Environment and Fisheries Department (SOAEFD).

\section{References}

Brady, N.C., 1984. The Nature and Properties of Soils. Ninth Edition. Macmillan Publishing Company. New York.

Cosby, B.J., Hornberger, G.M., Galloway, J.N. and Wright, R.F., 1985a. Modelling the effects of acid deposition: Assessment of a lumped parameter model of soil water and stream water chemistry Wat. Res., 21, 51-63.

Cosby, B.J., Hornberger, G.M., Galloway, J.N. and Wright, R.F., 1985b. Time scales of acidification: A quantitative model for estimating freshwater acidification Environ. Sci. Technol., 19, 1144-1149.

Department of the Environment (DOE), 1994. Critical loads of acidity in the United Kingdom. Institute of Terrestrial Ecology, Penicuik, Midlothian, Scotland.

Evans, C., Jenkins, A., Helliwell, R.C. and Ferrier, R.C., 1998. Predicting regional recovery from acidification; the MAGIC model applied to Scotland, England and Wales. Hydrol. Earth System Sci., 2, 543-554.

Fowler, D., Leith, I.D., Smith, R.I., Choularton, T.W., Inglis, D. and Campbell, G., 1995. Atmospheric inputs of acidity, sulphur and nitrogen in the UK. In: Acid rain and its impact: The critical loads debate. (R.W Battarbee (Ed)), Ensis Publishing, 17-25.

Hornung, M., Bull, K.R., Cresser, M., Hall, J.R., Langan, S.J., Loveland, P.J. and Smith, C., 1995a. An empirical map of critical loads of acidity for soils in Great Britain Environ. Pollut., 90, 301-310.

Hornung, M., Bull, K.R., Cresser, M., Ullyett, J., Hall, J.R., Langan, S., Loveland, P.J. and Wilson, M.J., 1995b. The sensitivity of surface waters of Great Britain to acidification predicted from catchment characteristics Environ. Pollut., 87, 207-214.

Hornung, M, Bull, K.R, Cresser, M, Hall, J, Loveland, P.J, Langan, S, Reynolds, B. and Robertson, W.H., 1995c. Mapping critical loads for the soils of Great Britain. In: Acid rain and its impact: the critical loads debate. (R.W. Battarbee (Ed)).

Jenkins, A., Renshaw, M., Helliwell, R.C., Sefton, C., Ferrier, R.C. and Swingewood, P., 1997. Modelling surface water acidiffation in the UK: application of the MAGIC model to sites in the UK Acid Waters Monitoring Netmork. Institute of Hydrology, Wallingford, UK, Report No. 131.

Kinniburgh, D.G. and Edmunds, W.M., 1986. The susceptibility of UK groundwaters to acid deposition. Hydrogeological Report, 86/3. British Geological Survey, Wallingford, UK.

Kreiser, A.M., Patrick, S.T. and Battarbee, R.W., 1993. Critical acidity loads for UK freshwaters-introduction, sampling strategy and use of maps. In: Critical loads: Concepts and applications (M. Hornung and R. Skeffington (Eds)). ITE Symposium No 28. HMSO, London.

Langan, S. and Wilson. M.J., 1994. Critical loads of acid deposition on Scottish soils. Wat., Air and Soil Pollut., 75, 177-191.

Langan, S., Sverdrup, H. and Coull, M., 1995. The calculation of base cation release from the chemical weathering of Scottish soils using the PROFILE model. Wat., Air and Soil Pollut., 85, 2497-2502. 
Le Bas, C. and Jamagne, M., 1996. Soil databases to support sustainable development. JRCEC-INRA-SESCPE Joint Publication, EUR 16371 EN, Orleans, France.

Nilsson, J. and Grennfelt, P., 1988. Critical loads for sulphur and nitrogen. Nordic Council of Ministers, Copenhagen, Denmark.

Reuss, J.O. and Johnson, D.W., 1985. Effects of soil processes on the acidification of water by acid deposition. 7. Environ. Qual, 14, 26-31.

Soil Survey of Scotland, 1984. Organisation and Methods of the 1:250 000 Soil Survey of Scotland. Macaulay Land Use Research Institute, Aberdeen.
Skiba, U. and Cresser, M.S., 1989. Prediction of long-term effects of rainwater acidity on peat and associated drainage water chemistry in upland areas, Wat Res., 23, 1477-82.

Sverdrup, H., de Vries, $W$, and Henriksen, A, 1990. Mapping Critical Loads: A guidance to the criteria, calculations, data collection and mapping of critical loads Miljorapport (Environmental report) 1990, 14, Nordic Council of Ministers, Copenhagen, Denmark. 